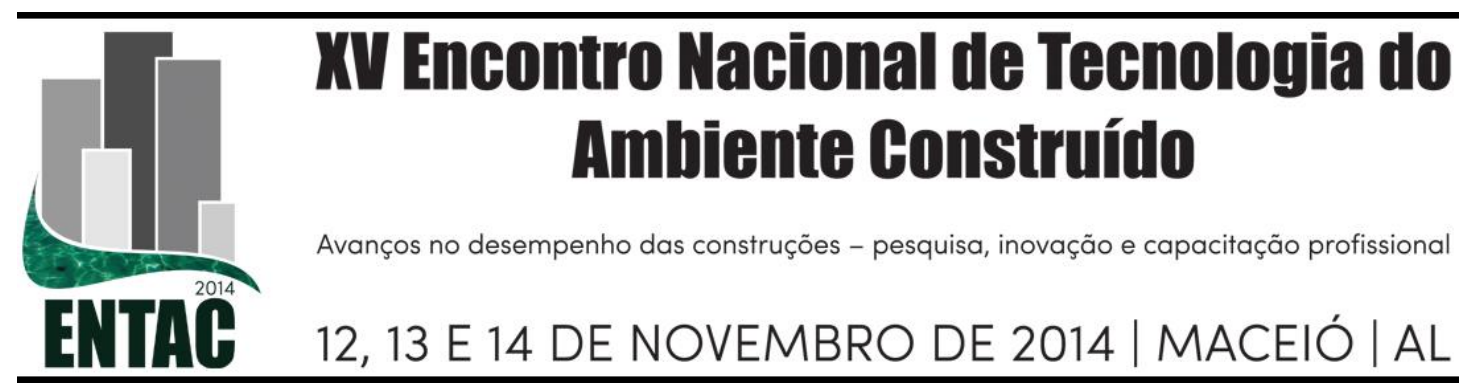

\title{
MANIFESTAÇÃO PATOLOGICA EM ESTRUTURAS METÁLICAS E MISTAS. PRÉDIO DA ESCOLA DE MINAS - UFOP
}

\author{
ANDRADE, Miguel (1); FERREIRA, Franciele M.C. (2); MELO, Mirvane \\ Vasconcelos Santos (3); SOUZA, Henor Artur de (4)
}

(1) UFOP, e-mail: andradejuniorarquitetura@ @otmail.com (2) IFMG, (31) 8902-2267, e-mail: fram013@yahoo.com.br (3) UFOP, e-mail: mirvanearquitetura@yahoo.com.br, (4) UFOP, e-mail: henorster@gmail.com

\begin{abstract}
RESUMO
Estruturas, de aço, concreto e madeira, não duram indefinidamente, se deterioram com o passar do tempo e não alcançam sua vida útil se não bem projetadas, executadas, utilizadas com critérios e, finalmente, submetidas a uma manutenção preventiva. O objetivo deste trabalho é avaliar as condições físicas do prédio da Escola de Minas - Universidade Federal de Ouro Preto - verificando as principais manifestações patológicas encontradas. Este trabalho foi dividido em duas etapas: primeiramente um levantamento bibliográfico dentro do contexto das manifestações patológicas em estruturas metálicas e mistas bem como dentro do assunto manutenção predial e, em seguida, realizado estudo de caso com uma avaliação das condições físicas do prédio da Escola de Minas da Universidade Federal de Ouro Preto UFOP - em Minas Gerais. O estudo apresenta caráter exploratório tendo em vista realizar estudo de campo para aprimorar os conhecimentos apresentados. Foram delimitadas duas áreas a serem mapeadas no pavimento térreo, primeiro bloco do edifício. A primeira exatamente no acesso principal e a segunda, próxima aos primeiros banheiros de acesso ao público, ainda no pavimento térreo. Foram utilizadas máquinas fotográficas, trena e fichas para catalogar as manifestações patológicas. A partir do mapeamento das áreas e após inspeção predial foram elaborados dois laudos técnicos com as fotografias das manifestações patológicas existentes e uma breve descrição de cada um dos casos encontrados. A partir dos levantamentos foi possível compreender as principais causas das manifestações patológicas como presença de microrganismos, umidade constante, baixa insolação etc. Foi possível identificar que o prédio da Escola de Minas não apresenta uma organização periódica de manutenção ficando o edifício sujeito a desgaste constante. O presente trabalho possui relevante contribuição no tema Durabilidade das Construções, levantando questões acerca da falta de uma política organizacional de manutenção nos prédios, principalmente os públicos e levando discussões pertinentes ao tema.
\end{abstract}

Palavras-chave: manifestações patológicas, aço e concreto, manutenção predial

\begin{abstract}
Structures, steel, concrete and wood do not last indefinitely, deteriorate over time and fail to reach their useful life if not properly designed, implemented, used with criteria and finally submitted to a preventive maintenance. The objective of this study is to evaluate the physical condition of the building of the School of Mines - Federal University of Ouro Preto - checking the main pathologies found. This work was carried out from a discipline master being divided into two stages : first a literature within the context of pathologies in steel and composite structures as well as within the subject building maintenance and then conducted a case study with a review the physical conditions of the building of the School of Mines, Federal University of Ouro Preto - UFOP - Minas Gerais. The present exploratory study in order to achieve field study to enhance the knowledge presented. Two areas were defined to be mapped on the ground floor, first block of the building. The first page in exactly the same access and the second, next to the first access to the public baths, still on the ground floor. Cameras, tape and plugs to catalog the
\end{abstract}


pathologies were used. From the mapping of areas and building inspection after two technical reports with photographs of existing conditions and a brief description of each of them were drafted. From the survey it was possible to understand the main causes of diseases such as the presence of microorganisms , moisture constant, low insolation etc. It was possible to identify that the building of the School of Mines has no periodic maintenance organization getting the building subject to constant wear. This work has significant contribution on the theme Durability of Constructions, raising questions about the lack of an organizational policy of maintaining the buildings, especially public and leading discussions relevant to the topic.

Keywords: pathologies, steel and concrete, building maintenance

\section{INTRODUÇÃO}

As anomalias construtivas e descuidos com a manutenção predial são causadores de danos pessoais e materiais significativos, tanto aos usuários e proprietários das edificações, como à sociedade em geral, devido à deterioração urbana que favorece o crime, afasta o turismo e reduz a auto-estima dos cidadãos.

Segundo o Instituto Brasileiro de Avaliações e Perícias de Engenharia de São Paulo (IBAPE, 2005), infiltrações, trincas, insuficiência de vagas de garagem, portas empenadas e outros problemas, aparentes ou ocultos, devem ser reparados na fase de garantia do imóvel, para evitar agravamentos posteriores. Danos causados por obra vizinha, choques de veículos em partes da edificação, vandalismos, etc., podem ameaçar seriamente o prédio, sugerindo-se a realização de perícia de engenharia para apuração dos danos e responsabilidades.

Segundo Andrade (2005), no Brasil, como em todo mundo, edificações de pequeno e grande porte, pontes, viadutos, túneis, obras hidráulicas, construções residenciais e comerciais, pela ação do tempo podem manifestar patologias que estão associadas com uma ou mais formas de deterioração. A problemática não esta relacionada às patologias e anomalias em si, e nem ao mecanismo de ocorrência das falhas dos sistemas de degradação das estruturas, mas, sim, ao curto tempo em que estão surgindo. Muitas vezes, com menos de 20 anos de uso as estruturas já necessitam de manutenção corretiva generalizada para prolongar sua vida útil.

Vida útil é o período no qual a estrutura cumpre sua função projetada sem custos importantes de manutenção, ou seja, deverá estar sob manutenção preventiva e não sofrer manutenção corretiva. (PIANCASTELLI, 1998).

O ideal de preservação seria que as edificações resistissem por um bom espaço de tempo nas condições ideais; mas este uso cria impacto que, mesmo nas condições de uso ideais, interfere no desempenho da edificação de forma intrínseca e extrínseca.

Causas intrínsecas da deterioração são as falhas de execução como: deficiências na concretagem, inadequação de escoramentos e fôrmas, deficiências nas armaduras, utilização incorreta dos materiais de construção, inexistência de controle de qualidade. Bem como as falhas durante a utilização, como a ausência de manutenção, além das causas denominadas como naturais e próprias à estrutura, as causas químicas e causas físicas. Devem ser consideradas também as causas extrínsecas como as falhas durante o projeto, defeitos de execução, falhas durante a utilização, sinistras ou causas fortuitas como: incêndio, inundações, acidentes entre outras. (PIANCASTELLI, 1998)

Não há dúvidas quanto à forte influência que o espaço construído exerce sobre a qualidade de vida da humanidade, já que a maior parte da população mundial habita em cidades, e vive essencialmente em edificações. $\mathrm{O}$ ambiente edificado se configura como suporte físico para a realização direta ou indireta de todas as atividades produtivas, e por isso representa um papel social fundamental. 
Além disto, as construções têm alto valor patrimonial. O edifício se constitui em um dos maiores patrimônios de qualquer pessoa ou empresa, em geral com elevado valor de uso e de troca, desde que mantido em boas condições. Ainda, há que se considerar também o valor afetivo da edificação. No caso brasileiro faz parte da cultura a grande estima pelo ambiente construído, o edifício concebido como patrimônio a ser legado aos herdeiros, como que de duração eterna.

Apesar da busca incessante por maior solidez e tecnologia na construção civil, sabe-se que, a princípio, qualquer bem possui durabilidade limitada, e é natural que sofra depreciação ao longo do tempo. Nenhuma edificação está imune à degradação provocada pelo ambiente, pelo uso ou mesmo pelas características de seus materiais constituintes. No entanto, o passar do tempo não é determinante para o estado de conservação de um edifício, sendo possível que o processo inevitável de depreciação se torne consideravelmente mais lento, por meio de atividades de conservação e manutenção do ambiente construído. (BARBOSA; PUSCH, 2011)

Em estudos realizados pelo Instituto Brasileiro de Avaliações e Perícias de Engenharia de São Paulo (IBAPE, 2005), foi verificado que mais de $60 \%$ dos acidentes ocorridos em edifícios com mais de 10 anos estão relacionados à deficiência ou inexistência de manutenção, perda precoce de desempenho e degradação acentuada. O estudo ainda concluiu que em mais da metade dos acidentes avaliados houve o colapso parcial ou total do sistema estrutural, ora por falta de manutenção, ora por erros de projeto ou de execução daí a importância desse trabalho.

\subsection{Manifestações patológicas em estruturas mistas}

Segundo o Instituto Brasileiro de Avaliações e Perícias de Engenharia de São Paulo (IBAPE, 2005) pode-se definir corrosão como a interação destrutiva de um material com o ambiente, seja por reação química, ou eletroquímica. Basicamente, são dois os processos principais de corrosão que podem sofrer as armaduras de aço para concreto armado: a oxidação e a corrosão propriamente dita.

Por oxidação entende-se o ataque provocado por uma reação gás-metal, com formação de uma película de óxido. Este tipo de corrosão é extremamente lento à temperatura ambiente e não provoca deterioração substancial das superfícies metálicas, salvo se existirem gases extremamente agressivos na atmosfera.

De acordo com Junior (2008) por corrosão entende-se o ataque eletroquímico que ocorre em meio aquoso. A corrosão acontece quando é formada uma película de eletrólito sobre a superfície dos fios ou barras de aço. Esta película é causada pela presença de umidade no concreto, salvo situações especiais e muito raras, tais como dentro de estufas ou sob ação de elevadas temperaturas $\left(>80^{\circ} \mathrm{C}\right)$ e em ambientes de baixa umidade relativa $(<50 \%)$. Este tipo de corrosão é também responsável pelo ataque que sofrem as armaduras quando ainda armazenadas no canteiro. É melhor e mais simples preveni-la do que tentar saná-la depois de iniciado o processo.

As fissuras do concreto facilitam o acesso do meio corrosivo a aceleram o processo. Quando as fissuras atingem a superfície externa do concreto, os produtos da corrosão podem ser removidos. Mais graves são os ataques em concreto protendido. Neste caso o processo de corrosão pode levar a perda da resistência e eventualmente colapso. (IBAPE, 2005) 


\subsection{Manifestações patológicas em estruturas de aço}

Segundo Pravia e Betinelli (2013) as manifestações patológicas mais comuns em estruturas de aço podem ser definidas em seis tipos principais, conforme mostrados no quadro1.

\section{Quadro 1 - Manifestações patológicas em estruturas de aço}

\begin{tabular}{|l|l|}
\hline Manifestações patológicas no aço & \multicolumn{1}{c|}{ Principais causas } \\
\hline Corrosão localizada & $\begin{array}{l}\text { Causada por deficiência de drenagem das águas } \\
\text { pluviais e deficiências de detalhes construtivos, } \\
\text { permitindo o acúmulo de umidade e de agentes } \\
\text { agressivos. }\end{array}$ \\
\hline Corrosão generalizada & $\begin{array}{l}\text { Causada pela ausência de proteção contra o } \\
\text { processo de corrosão. }\end{array}$ \\
\hline Deformações excessivas & $\begin{array}{l}\text { Causadas por sobrecargas ou efeitos térmicos não } \\
\text { previstos no projeto original, ou ainda, deficiências } \\
\text { na disposição de travejamentos. }\end{array}$ \\
\hline Flambagem local ou global & $\begin{array}{l}\text { Causadas pelo uso de modelos estruturais } \\
\text { incorretos para verificação da estabilidade, ou } \\
\text { deficiências no enrijecimento local de chapas, ou } \\
\text { efeitos de imperfeições geométricas não } \\
\text { consideradas no projeto e cálculo. }\end{array}$ \\
\hline Fratura e propagação de fraturas & $\begin{array}{l}\text { Falhas estas iniciadas por concentração de tensões, } \\
\text { devido a detalhes de projeto inadequados, defeitos } \\
\text { de solda, ou variações de tensão não previstas no } \\
\text { projeto. }\end{array}$ \\
\hline
\end{tabular}

Fonte: PRAVIA; BETINELLI, 2013

A corrosão é um tipo de deterioração que pode ser facilmente encontrada em obras metálicas e se caracteriza como um fenômeno patológico de maior conhecimento público. O aço oxida quando em contato com gases nocivos ou umidade, necessitando por isso de cuidados para prolongar sua durabilidade.

Segundo Castro (1999) como o fenômeno da corrosão envolve vários tipos de mecanismos, é importante conhecê-los para que, no caso de sua ocorrência, se possa rapidamente estabelecer um diagnóstico.

A Inspeção Predial é fonte de informação para a manutenção, apresentada por meio de laudo com o levantamento de anomalias, sua classificação quanto ao risco e urgência de cada uma delas, gerando lista de prioridades com orientações técnicas e informando o estado de conservação da edificação.

Falhas de manutenção ou ausência de manutenção preventiva, derivando numa possível degradação acelerada da estrutura, podem comprometer a sua segurança.

\section{METODOLOGIA}

Este trabalho foi realizado em duas etapas: primeiramente um levantamento bibliográfico dentro do contexto das manifestações patológicas em estruturas metálicas e estruturas mistas bem como dentro do assunto de manutenção predial e, em seguida, uma avaliação das condições físicas do prédio da Escola de Minas da Universidade Federal de Ouro Preto - UFOP - em Minas Gerais (Figura 1), levantando minuciosamente as manifestações patológicas encontradas nas estruturas metálicas e estruturas mistas. 
Figura 1 - Vista do prédio da Escola de Minas - UFOP

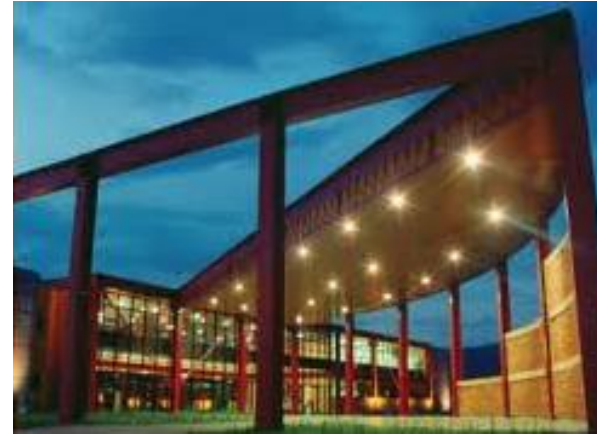

(a) Hall de entrada

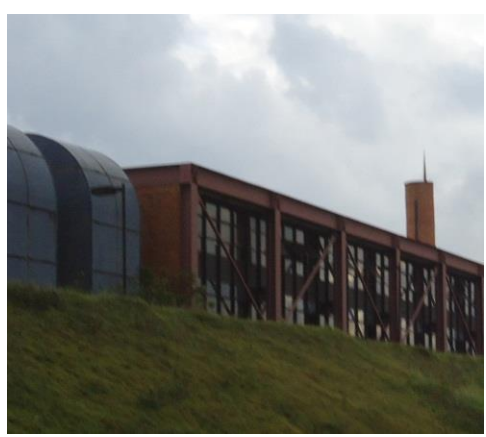

(b) Vista lateral

Fonte: BASTOS, 2008

Foram delimitadas duas áreas a serem mapeadas no pavimento térreo $\mathrm{A}$ e $\mathrm{B}$, primeiro bloco do edifício conforme mostrado na figura 2.

Figura 2 - Áreas mapeadas no prédio da Escola de Minas - UFOP

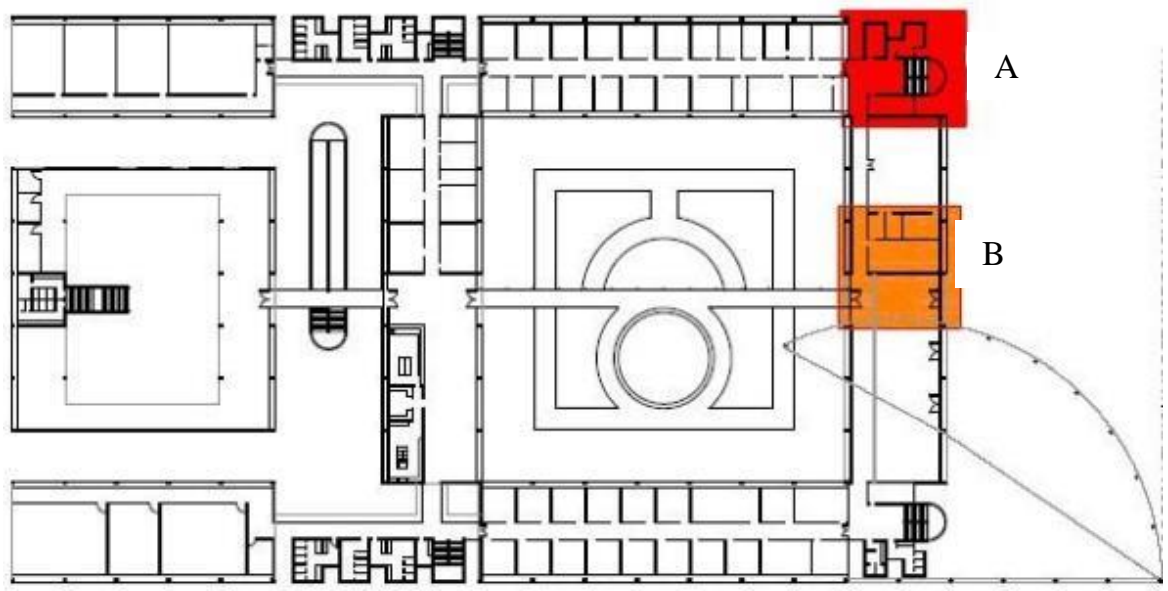

Fonte: BASTOS, 2008

A partir do mapeamento das áreas A, B e após inspeção predial foram elaborados dois laudos técnicos com as fotografias das manifestações patológicas existentes e uma breve descrição de cada um dos casos encontrados.

\section{RESULTADOS}

No quadro 2 descreve-se a situação da área A (Figura 2), externamente ao edifício, com breve comentário das manifestações patológicas encontradas.

No quadro 3 evidencia-se a situação da área B (Figura 2), também com breve descrição das manifestações patológicas encontradas. 
Quadro 2 - Patologias identificadas no estudo de caso - Área A (Figura 2)

\begin{tabular}{|l|l|}
\hline \multicolumn{1}{|c|}{ Imagem } & \multicolumn{1}{|c|}{ Descrição } \\
\hline & $\begin{array}{l}\text { Corrosão da esquadria do banheiro feminino } \\
\text { com a presença constante de umidade. } \\
\text { Percebe-se desestabilização da pintura e } \\
\text { reboco pulverulento na moldura e vidro solto } \\
\text { em uma das laterais. }\end{array}$ \\
\hline & $\begin{array}{l}\text { Alma vazada da viga metálica de sustentação } \\
\text { do edifício sem vedação, criando ambiente de } \\
\text { umidade constante. }\end{array}$ \\
\hline & $\begin{array}{l}\text { Estrutura exposta diretamente ao solo, } \\
\text { constante presença de umidade. }\end{array}$ \\
\hline & $\begin{array}{l}\text { Desenvolvimento de micro-organismos } \\
\text { devido à alta incidência de umidade e baixa } \\
\text { insolação. }\end{array}$ \\
\hline am a exposição à umidade seja transmitida de \\
\hline
\end{tabular}

\section{Quadro 3 - Patologias identificadas no estudo de caso - Área B (Figura 2) (continua)}

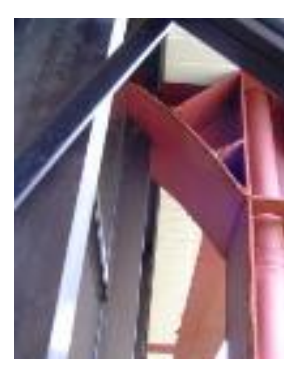

Formação de pites de corrosão nas extremidades da estrutura evidenciando este como um ponto frágil que merece um tratamento diferenciado contra esta patologia. Presença de sujidades. 


\section{Quadro 3 - Patologias identificadas no estudo de caso - Área B (Figura 2) (conclusão)}

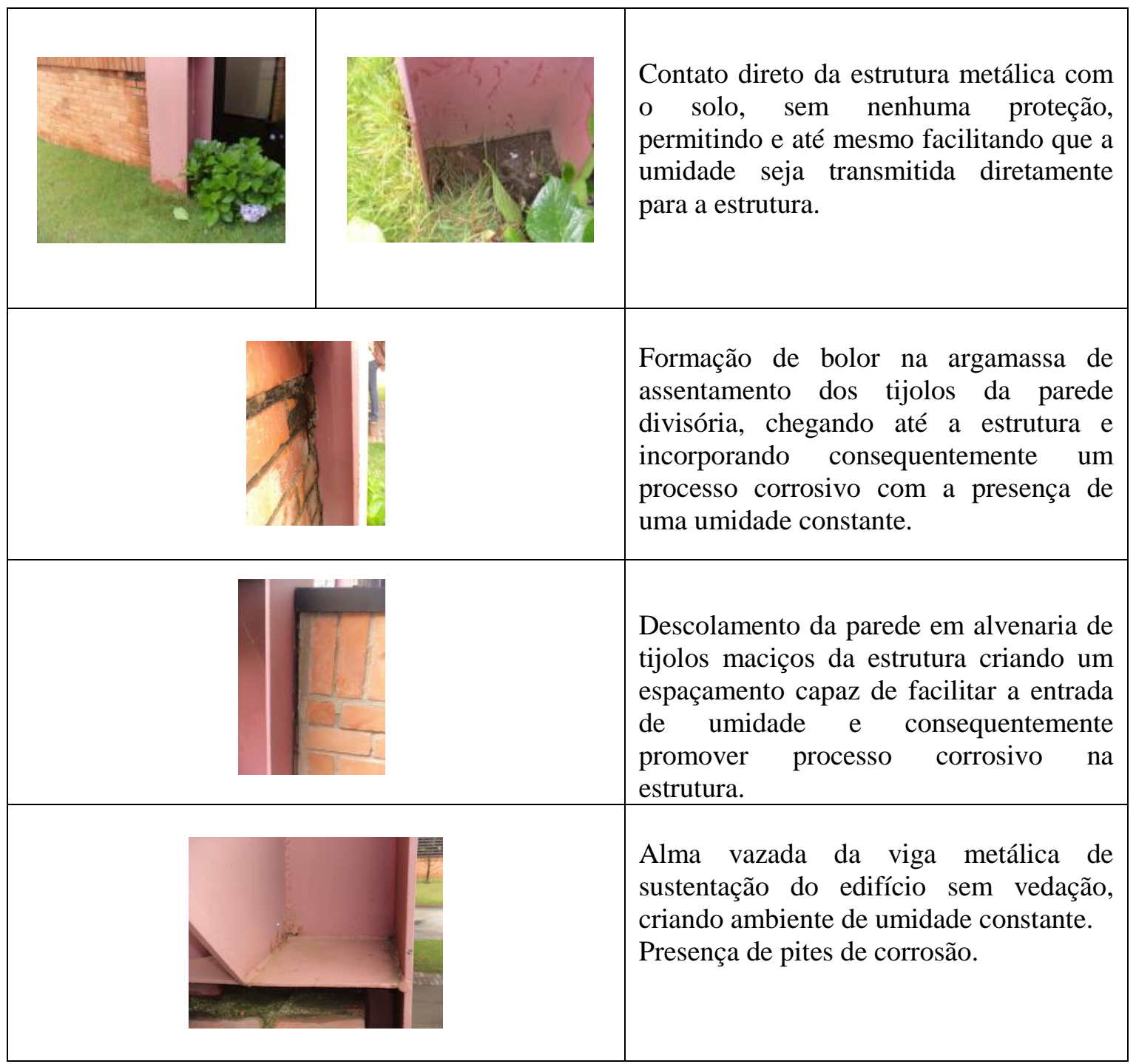

No ano de 2008 foi realizada uma inspeção predial para averiguar a situação do edifício naquele período e dentro dessas mesmas áreas foram encontradas as seguintes realidades, como mostrado nos quadros 4 e 5 .

A partir das entrevistas que foram realizadas naquele período com engenheiros responsáveis sobre os serviços de manutenção do campus verificou-se que as manutenções eram basicamente corretivas, atuando principalmente em serviços imediatos como troca de lâmpadas, substituição de bucha de torneiras, etc. 


\section{Quadro 4 - Patologias identificadas no estudo de caso em 2008- Área A (Figura 2)}

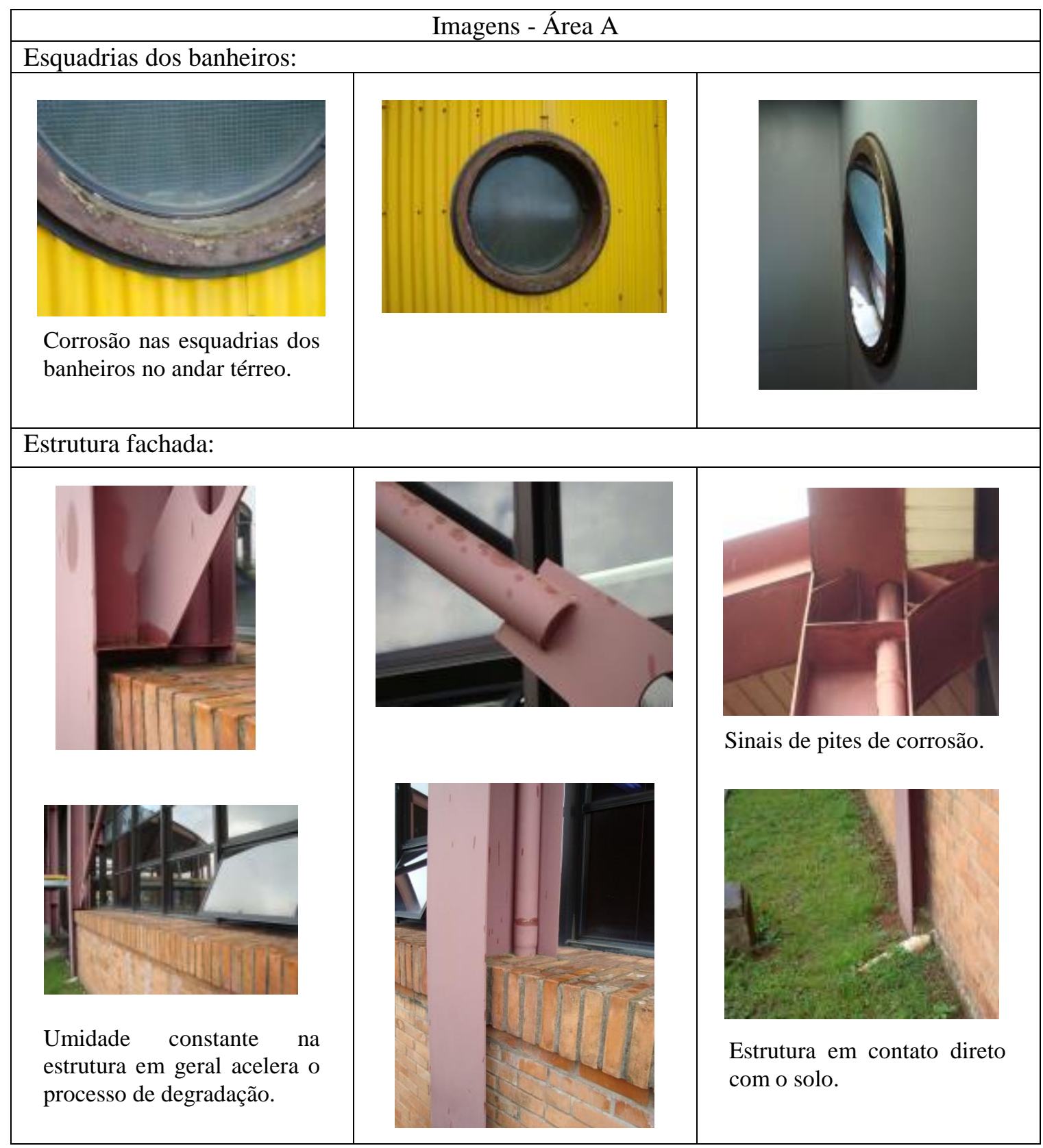

Fonte: BASTOS, 2008. 
Quadro 5 - Patologias identificadas no estudo de caso em 2008 - Área B (Figura 2)

\begin{tabular}{|l|l|l|}
\hline \multicolumn{3}{|c|}{ Imagens - Área B } \\
\hline Acesso Principal: & \multicolumn{1}{|c|}{$\begin{array}{l}\text { Estrutura em contato direto } \\
\text { com o solo favorecendo o } \\
\text { aparecimento } \\
\text { manifestações patológicas. }\end{array}$} \\
\hline Manchas na estrutura & \begin{tabular}{l} 
de \\
\hline
\end{tabular} & $\begin{array}{l}\text { Surgimento de pites de } \\
\text { corrosão em algumas regióes } \\
\text { da estrutura. }\end{array}$ \\
\hline
\end{tabular}

Fonte: BASTOS, 2008.

A manutenção corretiva definida pela norma NBR 5674 (ABNT, 2012) é a estratégia menos recomendada, uma vez que, além dos custos inviáveis da correção imprevista, também é possível que hajam patologias não identificadas, ou não apontadas, pelos usuários, que vão se agravando com o tempo e acabam por definir a degradação e envelhecimento precoce do edifício, bem como a redução da vida útil de equipamentos, máquinas e instalações.

Percebe-se a necessidade de criação de um programa de manutenção preventiva para reestabelecer as condições físicas do edifício.

\section{CONSIDERAÇÕES FINAIS}

De um modo geral, a análise comparativa realizada no presente trabalho permite concluir que, num período de tempo de aproximadamente seis anos, houve uma degradação significativa no processo evolutivo das manifestações patológicas apresentadas em 2008, Quadros 4 e 5 (BASTOS, 2008), presentes no objeto de análise. Foram encontrados, nos locais estudados, micro-organismos, sinais de umidade constante, baixa insolação etc. Como também se constataram falhas ou ausência de manutenção preventiva, derivando numa possível degradação acelerada das condições físicas do prédio, podendo comprometer a sua segurança.

Esta conclusão acaba se constituindo num relevante subsidio para os responsáveis pelas condições físicas do prédio da Escola de Minas da Universidade Federal de Ouro Preto - UFOP - em Minas Gerais, nas condições abrangidas pelo estudo realizado. Constata- 
se que a manutenção predial definida pela norma NBR 14037 (ABNT, 2011), seja ela realizada para conservar ou recuperar a capacidade funcional da edificação e de suas partes, valoriza sobremaneira a pratica da inspeção predial. Esta norma sugere que se desenvolvam programas de manutenção preventiva e corretiva na construção civil.

Observa-se que a comparação foi feita nos mesmos pontos com um espaço de tempo em que, neste interstício, foi reformulada a norma citada anteriormente, para reforçar a compreensão da importância de operação e de manutenção das edificações.

Este é um exemplo da necessidade imediata da prática da manutenção corretiva no prédio estudado neste trabalho, com o estabelecimento de novos e eficientes procedimentos para a recuperação dos sistemas e elementos construtivos da edificação.

Apresentadas as deficiências, expostas as carências de manutenção, fica a sugestão de um trabalho que trate de cada uma, detalhadamente, sob a luz da norma NBR 14037 (ABNT, 2011).

\section{Agradecimentos}

Os autores agradecem ao apoio da UFOP, IFMG, FAPEMIG, CAPES e CNPq por este trabalho.

\section{REFERÊNCIAS}

ANDRADE, T. W. C. O. Considerações sobre durabilidade, patologia e manutenção das estruturas. Tecomat - Tecnologia da Construção e Materiais Ltda. São Paulo, 2005. 1-14 p.

ASSOCIAÇÃO BRASILEIRA DE NORMAS TÉCNICAS. NBR 14.037: Diretrizes para elaboração de manuais de uso, operação e manutenção das edificações - Requisitos para elaboração e apresentação dos conteúdos. Julho de 2011.

ASSOCIAÇÃO BRASILEIRA DE NORMAS TÉCNICAS. NBR 5674: Manutenção de edificações - Requisitos para o sistema de gestão de manutenção. Julho de 2012.

BARBOSA, P. B.; PUSCH, J. Da intenção de projeto ao uso do edifício: a busca da excelência profissional. Programa de Excelência em Projetos CREA-PR. Curitiba, 2011.

BASTOS, M. A. R. Manutenção predial: Estudo de caso Escola de Minas. Relatório interno: PROPEC. 32 p. Ouro Preto, 2008.

CASTRO, E. M. C. de. Patologia dos edifícios em estruturas metálicas. 1999, 202 p. Dissertação (Mestrado em Engenharia Civil) - Escola de Minas, Universidade Federal de Ouro Preto, Ouro Preto, 1999. UFOP.

INSTITUTO BRASILEIRO DE AVALIAÇÕES E PERÍCIAS DE ENGENHARIA DE SÃO PAULO - IBAPE. Inspeção Predial: check-up predial: guia da boa manutenção. São Paulo - Liv. e Ed. Universitária de Direito, 2005.

JUNIOR, C. C. S. Técnicas de recuperação de estruturas de concreto armado sob efeito da corrosão das armaduras. Belo Horizonte: Universidade Federal de Minas Gerais. DEMC, 2008.

PIANCASTELLI, E. M. Patologia, recuperação e reforço de estruturas de concreto armado. Belo Horizonte: Universidade Federal de Minas Gerais, 1998. 160p. Notas de Aula.

PRAVIA, Z. M. C.; BETINELLI, E. A. Falhas em estruturas metálicas: Conceitos e estudos de caso. Curso de Engenharia Civil da FEAR - UPF. Disponível em:<Portal metálica>. Acesso em: 22 out. 2013. 